NBER WORKING PAPER SERIES

\title{
COMPENSATING WAGE DIFFERENTIALS \\ FOR MANDATORY OVERTIME
}

Ronald G. Ehrenberg

Paul L. Schumann

Working Paper No. 805

NATIONAL BUREAU OF ECONOMIC RESEARCH

1050 Massachusetts Avenue

Cambridge MA 02138

November 1981

Professor of Economics and Labor Economics, Cornell University, and Assistant Professor of Industrial Relations, University of

Minnesota. Our research was conducted under a contract with the Minimum Wage Study Commission, however the views expressed here are solely our own. Earlier versions of this paper were presented at the Winter 1980 Econometric Society Meetings and at seminars at the National Bureau of Economic Research (Palo Alto), Michigan State University, the University of Arizona, and Tel-Aviv University. Without implicating them for what remains, we wish to thank the participants of these sessions, as well as numerous colleagues at Cornell and elsewhere for their comments. We also wish to express our gratitude to Eileen Driscoll for her assistance with some of the computations and to our colleague, William Greene, for providing us with a copy of his econometric program that estimates equations, controlling for selectivity bias. The research reported here is part of the NBER's research program in Labor Studies. Any opinions expressed are those of the authors and not those of the National Bureau of Economic Research. 
NBER Working Paper \# 805

November 1981

COMPENSATING WAGE DIFFERENTIALS

FOR MANDATORY OVERTIME

\begin{abstract}
Our paper estimates the extent to which employees are compensated
\end{abstract} for an unfavorable job characteristic, being required to accept mandatory assignment of overtime, by receiving higher straight-time wages. Our estimating equations are derived from a model in which wage rates and the existence of mandatory assignment of overtime are jointly determined in the market by the interaction of employee and employer preferences. While on average, we do not observe the existence of a compensating wage differential for mandatory overtime, we do observe the existence of such differentials for unionized workers and workers with only a few years experience at a firm. Given any estimated compensating wage differential for an unfavorable working condition, one must decide whether its magnitude is sufficiently large to allow one to conclude that the differential fully compensates workers for the disutility of being subject to the unfavorable working condition. We develop and illustrate a methodology that can be used to answer this question, at least for the case of mandatory overtime provisions and other rules that restrict employees' choice of hours.

Ronald G. Ehrenberg

Paul L. Schumann

New York State School of Industrial and Labor Relations Cornell University P.O. Box 1000 Ithaca, NY 14853 (607) $256-3026$ 


\section{Introduction}

The overtime pay premium provisions of the Fair Labor Standards Act (FLSA) currently regulate only two dimensions of the hours of work relationship; the number of hours after which the overtime premium goes into effect (40) and the premium's level (time and a half). In their legislation several European countries regulate other dimensions; for example they require either prior governmental approval for overtime and/or for employees to give their consent to working overtime. ${ }^{1}$ A bill to amend the FLSA introduced recently into Congress, would have similarly prohibited mandatory assignment of overtime in the United States. ${ }^{2}$

A rationale for many forms of protective labor legislation is that they are attempts to correct for failures of private markets and overtime hours legislation can be analyzed with this in mind. ${ }^{3}$ For even if both employers and their employees were satisfied with long workweeks and no premium pay for overtime, their private calculations ignore the social costs of unemployment. An overtime premium can be thought of as a tax to make employers bear the full marginal social cost of their hours decisions; its intent is to reduce the use of overtime hours and stimulate employment growth. The payment of the premium directly to employed workers may be justified if market imperfections prevent workers from freely choosing their desired workweeks and force them to work "excessively" long hours. The payment can then be seen as an attempt to reduce their disutility from long workweeks.

Proposals to legislate prohibitions against mandatory overtime can be viewed as being based upon the belief that market imperfections persist in the labor market and that the overtime premium does not fully compensate employees for the disutility associated with mandatory overtime. However, one may question if markets have failed here; there appear to be a variety 
of overtime hours provisions offered in the labor market. For example, only 16 percent of the individuals in the 1977 Michigan Quality of Employment Survey, who reported working overtime, also reported that the overtime hours decision was made unilaterally by their employer and that overtime was mandatory, in the sense that employees who refused it suffered a penalty. ${ }^{4}$ In addition, roughly 20 percent of employees covered by major collective bargaining agreements in 1976 had explicit provisions in their contracts that gave them the right to refuse overtime. 5

To the extent that labor markets are competitive and establishments do offer a variety of overtime hours provisions (i.e., employer determines, employee determines, penalty for refusal, etc.), compensating wage differentials should arise. That is, establishments which offered "distasteful" mandatory overtime provisions would have to pay either higher straight-time wages, higher overtime premiums, or higher fringe benefits to attract labor than would establishments in which such provisions did not occur. If straight-time wage, overtime premium, or fringe benefit differentials exist that fully compensate employees for the disutility of mandatory overtime provisions, no case for legislated prohibitions against mandatory overtime is present. ${ }^{6}$ As such, evidence on the extent to which such compensating differentials currently do exist is of importance to policymakers. 7

Our paper first attempts in the next section to estimate the extent to which employees currently are compensated, in the form of higher straighttime wages, for being required to work mandatory overtime. Our focus is on compensating straight-time wage differentials because the data base we use, the 1977 Michigan Quality of Employment Survey (QES), contains no information on the value of fringes and because preliminary analyses suggested that the 
magnitude of the overtime premium was not correlated with the presence of mandatory overtime rules, other variables held constant. Our estimating equations are derived from a model in which wage rates and the existence of mandatory assignment of overtime are jointly determined in the market; an employee's willingness to work mandatory overtime is positively related to the premium he would receive for working mandatory overtime, while an employer's demand for mandatory overtime provisions is negatively related to the premium he would have to pay to institute this work rule. Such a model leads naturally to the estimation of wage equations, using econometric techniques that correct for the sample selectivity problem.

Our empirical analyses do not provide strong support for the proposition that on average employees who work for establishments with mandatory overtime provisions tend to receive higher straight-time wages, ceteris paribus. On the other hand, they do suggest that there is a straight-time wage premium associated with mandatory overtime provisions for union workers and for workers with only a few years experience with a firm. We provide explanations for why these results might occur.

Given any estimated compensating wage differential for an unfavorable working condition, one must decide whether its magnitude is sufficiently large to allow one to conclude that the differential fully compensates workers for the disutility of being subject to the unfavorable working condition. In Section III we develop a methodology that can be used to answer this question, at least for the case of mandatory overtime provisions and other rules that restrict employees' choice of hours. The methodology requires one to estimate the parameters of an explicit utility function and then to use these estimates to compare the utflity that a representative 
worker would achieve when employed in situations in which mandatory overtime provisions are, and are not present. For expository convenience we use the simple Cobb-Douglas function to illustrate the methodology. The final section, then provides some brief concluding remarks.

II. Are There Compensating Wage Differentials Associated With Being

Required to Work Mandatory Overtime

Our goal is to estimate the extent to which individuals who are employed by firms that require mandatory overtime receive higher straight-time wages than otherwise identical individuals who are employed in firms in which overtime is voluntary. If the wage of the $i^{\text {th }}$ individual is $w_{i m}$ if he works in a firm in which overtime is mandatory and $W_{i v}$ if he works in a firm in which overtime is voluntary, then we can define the relative wage differential received for mandatory overtime, $d_{i}$, as

$$
d_{i}=\left(w_{i m}-w_{i v}\right) / w_{i v} \approx \log \left(w_{i m} / w_{i v}\right)
$$

In general it is not possible to observe both $W_{i m}$ and $W_{i v}$ with cross-section data, as at a point in time an individual is typically observed employed either by a firm that requires mandatory overtime or by a firm that does not, but not by both. ${ }^{8}$ A naive approach that circumvents this problem is to estimate wage equations separately for individuals in the mandatory and nonmandatory sectors, use the estimated coefficients from these regressions and the characteristics of a representative individual to compute predicted values of the wage rate that the individual would receive in both sectors, and then estimate the differential by calculating the percentage difference in these predicted values. 
More formally, suppose that we postulate that the wage rate an individual would receive in a job requiring mandatory overtime is a log linear function of a vector of variables, $\mathrm{x}$, which represent his personal characteristics (e.g., education, experience) and the characteristics of his employer (e.g., union status, establishment size, industry) plus a random error term $\left(\varepsilon_{i m}\right)$

$$
\log W_{i m}=\sum_{j=1}^{k} \alpha_{j m} x_{j i}+\varepsilon_{i m}
$$

and that a similar functional relationship exists that describes the wage that an individual would receive in a job in which overtime was voluntary

$$
\log _{i v}=\sum_{j=1}^{K} \alpha_{j v} x_{j i}+\varepsilon_{i v}
$$

The naive approach would involve estimating the parameters of (2) by ordinary least squares from observations on individuals who are required to work mandatory overtime and the parameters of (3) by ordinary least squares from observations on individuals who are not required to work mandatory overtime. Given estimates of these parameters $\left(\hat{\alpha}_{j m}, \hat{\alpha}_{j v}\right)$ and the characteristics of a representative individual and his employer $\left(X_{j i}\right)$, one can then obtain an estimate of the relative straight-time wage premium paid for mandatory overtime by

$$
\hat{\mathrm{d}}_{i}=\log \hat{\mathrm{h}}_{i m}-\log \hat{\mathrm{w}}_{i v}=\sum_{j=1}^{K}\left(\hat{\alpha}_{j m}-\hat{a}_{j v}\right) \mathrm{x}_{j i}
$$

As is now well-known, however, estimates of wage equations from truncated samples will not necessarily yield unbiased estimates of the underlying structural wage equations, since the assumption that the error term 
in each equation is random and uncorrelated with the other explanatory variables is typically violated. ${ }^{9}$ This occurs because employees and employers are not randomly assigned to the mandatory overtime sector, but rather make explicit choices. Estimates of the wage equation that ignore the underlying choice model will be biased because they will confound the effect of an explanatory variable on wages with its effect on the probability that an individual is, or is not, employed by a firm that requires mandatory overtime. To correct for this sample selectivity problem requires us to model the underlying economic choice process that determines whether an individual is observed working mandatory overtime.

This problem is complicated by the fact that such an event is a product of both employee and employer decisions. The straight-time wage premium pald for mandatory overtime will influence both employees' willingness to be employed in establishments that require mandatory overtime and employers' demands that their employees work mandatory overtime. Other things equal, the larger the premium the greater employees' willingness to accept this working condition and the smaller employers' demands to have their employees accept it.

An employee's willingness to be required to work mandatory overtime Is also undoubtedly related to a vector of personal characteristics and characteristics of his employer that influence his desire to regularly work long workweeks. For example, older employees, employees with "home responsibilities", and employees working in firms with unpleasant working conditions might, ceteris paribus, prefer not to be required to work mandatory overtime. Similarly, an employer's demand for the provision is also related to a vector of employee and firm characteristics that influence 
the net benefits of having mandatory overtime provisions. For example, an employer operating a firm in a continuous process industry, or in other situations in which the firm's technology depends upon the simultaneous presence of labor and capital or different categories of labor, might perceive it to be important to have mandatory overtime provisions. 10 Similarly, he might believe it more important to have such provisions for skilled production workers, where an absence might otherwise create a "bottleneck", than for unskilled clerical workers.

One can formally model the assignment of workers to the mandatory overtime or voluntary overtime sector in the context of a model in which employers have demand functions for mandatory overtime provisions, employees have supply functions that indicate their willingness to work for employers that offer such provisions, and the assumption is made that an employee will be found in a job requiring mandatory overtime if, and only if, both he and the employer believe that it is in their best interests to have such a provision. $^{11}$ Under the appropriate assumptions about the error terms in the demand and supply equations (joint normally distributed) the equilibrium assignment rule is seen to be generated by a truncated bivariate probit model. $^{12}$

Unfortunately softward limitations and our inability to make a sufficlent number of a priori restrictions to identify all of the parameters of this model have prevented us from estimating the complete model ((I)-(3) plus the assignment rule) either by maximum likelihood methods or by an Iterative approach that leads to consistent estimates. Rather, we have assumed that the assignment rule can be approximated by the univariate probit model 


$$
\text { (5) } \begin{aligned}
S_{i}^{*} & =\delta_{0} d_{i}+\sum_{r=1}^{R} \delta_{r} Y_{r i}+u_{i} \\
s_{i} & =1 \text { if } S_{i}^{*}>0 \\
& =0 \text { otherwise. }
\end{aligned}
$$

Here $S_{1}^{*}$ is an unobservable continuous variable that indicates the "strength" of employer and employee preferences for mandatory overtime provisions. This variable can be arbitrarily scaled so that when it exceeds zero mandatory overtime is observed $\left(S_{i}=1\right)$, otherwise mandatory overtime is not observed $\left(S_{i}=0\right)$. The $\mathrm{Y}_{\mathrm{r}}$ are a set of variables (in addition to the wage differential, $d_{i}$ ) that influence either employees' willingness to work mandatory overtime or employers' desire to have such a working condition. Finally, $u_{i}$ is a normally distributed random error term and the $\delta^{\prime}$ s are parameters to be estimated.

Consistent estimates of the model specified in (1)-(5) can be obtained using an iterative procedure originally suggested by Lung-fei Lee (1978) and James Heckman (1979). ${ }^{13}$ One can substitute the wage equations (2) and (3) into (1) and then (5) to obtain a reduced form probit selection model in which the probability of observing an individual working mandatory overtime 18 specified to be a function of all of the predetermined variables in the model (the $X_{j}$ and $Y_{r}$ ). From estimates of this probit equation, one can compute estimates of variables (the inverse of the Mills ratio -- see lleckman (1979)) which are then added to the wage equations ((2) and (3)) to control for the probability that an individual is observed working mandatory overtime. These "augmented" wage equations can then be estimated by ordinary least squares and consistent parameter estimates of equations (2) and (3) 
obtained. 14 Finally, these estimated parameters and the mean values of the explanatory variables can be substituted back into (4) to compute consistent estimates of the straight-time wage differential associated with the presence of mandatory overtime provisions.

The data we use to implement the above framework come from the 1977 Michigan Quality of Employment Survey. ${ }^{15}$ We eliminated from the original 1515 individuals in the survey who were employed full-time those individuals who failed to report their straight-time hourly wage rate and/or whether they were required to work mandatory overtime. An individual was said to be required to work mandatory overtime if he or she reported that he or she could not refuse to work overtime without a penalty. This left us with a usable sample of 1108 observations, of which 165, or 14.89 percent, were categorized as being employed in a job that required mandatory overtime.

Columns (1) and (2) of Table 1 present OLS estimates of wage equations (equations (2) and (3)), estimated separately for individuals in the mandatory overtime and nonmandatory overtime, or voluntary overtime, sectors. We estimated three equations for each sector to permit us to test later for the sensitivity of our estimated differential to the specification of the wage equation used. The first is a standard human capital model, augmented by a variable indicating whether the individual is a union member or covered by a union contract $\left(\mathrm{x}_{8}\right)$ and includes measures of the individual's total labor market experience $\left(x_{1}, x_{2}\right)$, of his or her experience with the current employer $\left(x_{3}, x_{4}\right)$, of his or her years of formal schooling and trade school $\left(x_{5}, x_{6}\right)$, of his or her health status $\left(x_{7}\right)$, and measures of the respondent's sex $\left(x_{9}\right)$, race $\left(x_{10}\right)$, and marital status $\left(x_{11}\right)$. The second specification adds a vector of one-digit major occupation 
dichotomous variables. Finally, the third specification adds a vector of one-digit major industry dichotomous variables. For brevity, only the first specification is reported in the table. ${ }^{16}$ The pattern of coefficients in each equation is similar to the pattern found in previous studies that ignored the mandatory overtime question.

We also estimated several reduced form probit equations (equation (5)), one corresponding to each specification of the wage equations, that explain whether an individual is employed by a firm requiring mandatory overtime. The explanatory variables included in these equations are those that influence either employers' demands for an employee to work mandatory overtime or an employee's willingness to supply mandatory overtime, or that influence the wage paid in each sector, and hence the straight-time wage premium ((4)) paid for mandatory overtime. ${ }^{17}$ The pattern of coefficients did not vary across specifications and again for brevity we report only the simplest specification, which excluded the occupation and industry variables, in column (3) of Table 1. Many of the variables in these equations enter from both the employer and employee sides, and also from the wage equations. 18 Hence, it is difficult to predict what the expected signs of their coefficients should be in the reduced form probit model.

Column (3) indicates that while many of these variables' coefficients prove to be statistically insignificant, the chi-square statistic suggests that one can reject the hypothesis that the entire vector of coefficients is statistically insignificantly different from zero. Moreover, when we use these probit equations to compute predicted values of the inverse Mills ratios $\left(\lambda_{m 1}, \lambda_{v 1}\right)$, enter these variables in equations (2) and (3) respectively, and then reestimate these augmented wage equations using oLs, the selectivity variables prove to be statistically significant, at least 
at the .90 level of significance (Columns (4) and (5)). ${ }^{19}$ This provides some evidence that the estimated OLS wage coefficients may be inconsistent estimates of the true coefficients of the wage determination models, although as noted in footnote 13, the consistency of the estimates when we control for selectivity bias is condition upon (5) being the correct underlying selection rule.

The coefficient estimates contained in Table 1 can be used along with equation (4) to compute estimates of the straight-time wage premium paid to workers who are required to work mandatory overtime. We do this initially for a representative worker who has the mean value of each of the characteristics $(\mathrm{X})$ in the sample. The estimated premium is tabulated in the top row of Table 2 for each of the three specificatations of the wage equatiuns, for both the OLS and the selectivity corrected estimates. Quite strikingly, in only one of the $\mathbf{s} 1 \mathrm{x}$ cases is the estimated premium positive. On average, inarket forces do not seem to be producing a compensating wage differential for mandatory overtime.

Of course the fact that on average such a dfferential does not exist, does not imply that no workers in the economy are compensated for being required to work mandatory overtime. Two groups of workers that one might want to focus on, in particular, are those covered by collective bargaining agreements and those newly hired by firms.

Turning first to the role of collective bargalning, recently attention has been redirected to the many roles unions play in addition to seeking to Increase their members' wages. 20 Empirical studies have indicated that unlons may affect productivity and labor turnover. 21 In addition, it has been argued that unlons may help to compensate for market fallures by 
providing information on unfavorable working conditions and/or by obtaining compensating wage differentials for employees who are employed under such conditions. Indeed, a recent study suggests that up to two-fifths of the estimated union/nonunion wage differential is simply a compensating differential because unionized employees tend to be employed in more structured and hence less desirable (from the perspective of the employees) work settings. $^{22}$ Following this line of reasoning, one might hypothesize that unions will also achieve larger compensating wage differentials for mandatory overtime provisions for their members than those received by otherwise comparable nonunion employees. That is, markets may be sufficiently imperfect that compensating differentials might not arise in the absence of union pressure; unions may serve to help restore the differentials that would exist in the absence of these imperfections.

To test for this possibility, rows $B$ and $C$ of Table 2 present estimates of the percentage straight-time wage premium paid to workers required to work mandatory overtime in the union and nonunion sectors, respectively. These estimates again make use of the estimated wage equations; the differentials paid to union members are evaluated using the mean values of union members' characteristics, while those for nonunion members are evaluated at the mean values of nonunion employees' characteristics. 23 The estimated differentials are positive in the union sector but are negative in the nonunion sector. The OLS estimates suggest that the straighttime wage premium paid to induce workers to accept jobs which require mandatory overtime is roughly 4.0 to 5.3 percent in unionized establishments, while those that control for selectivity bias place the differential in the range of 2.6 to 4.3 percent. 
Turning next to the role of job tenure, it is also plausible that whether a premium is paid for mandatory overtime depends upon an employee's job tenure. If an employer seeks to attract a new employee to a firm that requires mandatory overtime and job applicants know of this unfavorable working condition, a compensating wage differential will be required. In contrast, employees who have been with a firm for a number of years and have accumulated "firm-specific" human capital, may find that there is a wedge between the wage they are receiving and the wage they can command from other employers. ${ }^{24}$ As such, ex post, the employer may not have to pay them a compensating wage differential for newly instituted unfavorable working conditions. 25 These employees' investments in firm-specific human capital limit the need for such differentials to arise.

This line of reasoning suggests that compensating wage differentials for mandatory overtime will be larger for empioyees with only a few years experience with a firm than they will be for long-term employees. To test this hypothesis, we divided our sample into employees with less than three years experience, and those with three or more years, with their current employer. OLS wage equations and the selectivity corrected wage equations were reestimated separately for each group and then the estimated straighttime wage premium paid to employers required to work mandatory overtime computed as before.

These estimated differentials are evaluated at the mean values of the characteristics for the individuals in each group and are reported in the last two lines of Table 2. The hypothesis appears to be borne out, at least for the OLS estimates. The OLS estimates suggest that positive compensating differentials for mandatory overtime are paid to inexperienced 
workers with less than three years of job tenure, however no such differential is paid to workers with more than three years job tenure. In contrast, the "selectivity corrected" estimates suggest that neither group receives a positive compensating differential for mandatory overtime. Since we have only approximated the true sample selection rule (sce footnote 13 and above), the statistical properties of the "selectivity corrected" estimates are not certain and it is not obvious which set of estimates should be considered preferred.

In sum, our results indicate that on average employees who work for establishments with mandatory overtime provisions do not receive compensatingly higher straight-time wages. Focusing on what happens "on average", however, masks important differences between groups. The data suggest that unionized employees do recelve a straight-time wage premium for fiandatory overtime; this provides support for the view (Duncan and Stafford (1980)) that one role unions play is to establish compensating wage differentals for unfavorable working conditions. The data also provide some weaker support for the view that experienced workers, who are "tled" to firms, fail to receive compensating wage differentials for mandatory overtime, but that workers with less than three years experfence with a firm do recelve such differentials. How one might attempt to judge whether the magntude of any estimated differental is sufficlent to fully compensate aployees for being subject to mandatory overtime provisions is an issue to whith we now turn. 
III. Are Compensating Wage Differentials for Mandatory Overtime Provisions "Fully" Compensating?

A long and growing literature in labor economics provides evidence on the existence of "compensating" wage differentials for various job characteristics. Among the characteristics examined have been risk of injury, nonwage forms of compensation (such as retirement system characteristics), working conditions, and risk of unemployment. ${ }^{26}$ A key question that policymakers must address is whether an estimated differential is sufficiently large to allow them to conclude that a worker is equally welloff with the job characteristic and the wage differential as he would be in the absence of the characteristic and the differential? If the answer is yes, if the differential is indeed "fully compensating", then the case for government intervention is substantially weakened.

If one truly believes that all labor markets are competitive, then it is almost a tautology that whatever wage differentials are generated by markets will be "fully compensating" ones. However, once one allows for market imperfections, the question becomes an empirical one. In some cases, It is possible to test whether the "compensating" differential is indeed "fully compensating". For example, Ehrenberg (1980) found that holding the factors that influence wages, promised retirement benefits, and the determinants of total compensation constant, that for every doilar that public employees were required to contribute to their pension fund, their annual earnings increased by a dollar. It is straightforward to conclude here that the wage differential associated with employee retirement system contributions are fully compensating.

In contrast, in other situations it is not easy to establish whether compensating differentials are fully compensating. Estimates of the 
compensating differential associated with the risk of fatal injury at the workplace suggest that individuals are paid a premium of 1 to 4 percent of their wages to compensate them for existing risks of fatal injuries. 27 However, researchers have not evaluated whether such differentials truly fully compensate workers for the risks of fatal injury; all we know is that they are the differentials observed in the market. If labor markets are not perfectly competitive, there is no reason to assume that the differentials are in fact fully compensating. Hence, the potential usefulness of these estimates for public policy in the occupational safety area is unclear.

In the case of mandatory overtime, or any other employment package that specifies a tied wage rate-hours of work bundle, it is possible to evaluate whether the compensating wage differentials that are observed are fully compensating. To understand the logic of our approach, refer to Figure 1 where a familiar indifference curve model is plotted. The individual is assumed to derive utility from leisure time and income; the latter is a proxy for some Hicksian composite commodity whose price is taken as fixed. Suppose an individual has nonlabor income of $O T$, a wage rate of $W_{0}$ for the first $\overline{\mathrm{H}}$ hours per week that he works, and he receives an overtime premium of time and a half for all overtime hours. The individual then faces the budget constraint BAOT and, given his indifference map, will locate at point a working $\mathrm{H}_{0}$ hours and having a total income of $\mathrm{Y}_{0}{ }^{\circ}$. Thus, his utility would be given by

(6)

$$
\mathrm{U}\left(\mathrm{Y}_{0}, \mathrm{~L}_{0}\right)
$$


Now suppose the individual was employed by a firm in which mandatory overtime was required and was forced to work $\mathrm{H}_{1}-\mathrm{H}_{0}$ more hours of overtime than he otherwise would choose. In this case he would wind up at point $b$ with a total income of $Y_{M}$. Although $Y_{M}$ exceeds $Y_{0}$, he obviously now would be at a lower level of utility. In fact, to leave him equally well off as he was at point $a$, if he is forced to work $\mathrm{H}_{1}$ hours he would require a total income of $\mathrm{Y}_{1} \cdot \mathrm{Y}_{1}-\mathrm{Y}_{\mathrm{M}}$ is the lump sum income transfer, or the compensating variation in income, that would be required to fully compensate him for the disutility associated with mandatory overtime.

Suppose, however, that instead of a lump sum payment, to get the employee to $\mathrm{Y}_{1}$ the employer offers him a straight-time wage $\mathrm{W}_{1}$ which is $d$ percent higher than before $\left(W_{1}=(1+d) W_{0}\right)$. It is easy to see that each value of the straight-time wage premium for mandatory overtime, $d$, will lead to a new budget line and that there is only one value of $d$ which will permit him to locate at point $e$ where his income will be $\mathrm{Y}_{1}$, his leisure hours $\mathrm{L}_{1}\left(=\mathrm{T}-\mathrm{H}_{1}\right)$ and where

$$
U\left(Y_{1}, L_{1}\right)=U\left(Y_{0}, L_{0}\right)
$$

This value of $d$, which leads to the budget line DCOT, is the fully compensating wage differential; the differential which fully compensates the individual for mandatory overtime. Provided that the individual's marginal utilities from income and leisure are both positive, and his indifference curves are convex, it is straightforward to show that higher values of d will more than fully compensate him, while lesser values will less than fully compensate him. Furthermore, how onerous mandatory overtime is depends upon the difference between $\mathrm{H}_{1}$ and $\mathrm{H}_{0}$; the larger this gap, the larger 
will be the straight-time wage premium necessary to fully compensate him for mandatory overtime. ${ }^{29}$ The analysis would of course be similar for any other tied wage-hours employment offer; for example, one could similarly analyze the compensating wage differential required to induce workers to accept jobs with shorter workweeks than they desire.

To operationalize this approach, and estimate what the fully compensating straight-time wage differential is, is no trivial task. In the present example, each individual either works for a firm requiring mandatory overtime or does not. Hence, we can directly observe either $W_{0}$ and $H_{0}$, or $W_{1}$ $\left(=\mathrm{W}_{0}(1+\mathrm{d})\right)$ and $\mathrm{H}_{1}$, but not both. Furthermore, it is necessary for us to know the shape of the individual's indifference curve, something which is typically not directly observed.

Fortunately, there is a way in which one can deduce all of the necessary information. To do so requires one to assume a specific functional form for the utility function. To illustrate the methodology, we assume for expositional convenience that the individual's utility function is any monotonic transformation of the Cobb-Douglas utility function.

(8) $\quad U=Y^{\alpha}{ }^{1-\alpha}$

If $\alpha$ were known, one could compute the level of utility achieved by a representative individual who was required to work mandatory overtime from

$$
\begin{aligned}
& \text { (9) } \mathrm{U}_{1}=\mathrm{Y}_{1}{ }^{\alpha} \mathrm{L}_{1}{ }^{1-\alpha} \\
& \text { where } \mathrm{Y}_{1}=\mathrm{W}_{1} \overline{\mathrm{H}}+\mathrm{W}_{1}(1.5)\left(\mathrm{H}_{1}-\overline{\mathrm{H}}\right)+\mathrm{M} \\
& \mathrm{L}_{1}=\mathrm{T}-\mathrm{H}_{1} .
\end{aligned}
$$


Here $W_{1}$ is the individual's observed wage, $H_{1}$ his observed weekly hours of work, $M$ his weekly nonlabor income, $\bar{H}$ the number of hours after which the overtime premium goes into effect (typically 40) and $T$ the total number of hours in a week (168).

Now given the utility function specified in (8), if this individual was employed by a firm which did not require mandatory overtime he would work $\mathrm{H}_{0}$ hours, where $\mathrm{H}_{0}$ is given by

$$
\begin{aligned}
\mathrm{H}_{0} & =\alpha \mathrm{T}+(\alpha-1)\left(M-.5 \mathrm{~W}_{0} \overline{\mathrm{H}}\right) / \mathrm{W}_{0}(1.5) & & \text { if } \mathrm{H}_{0}>\overline{\mathrm{H}} \\
& =\alpha \mathrm{T}+(\alpha-1)\left(\mathrm{M} / \mathrm{W}_{0}\right) & & \text { if } \mathrm{H}_{0} \leq \overline{\mathrm{H}}
\end{aligned}
$$

That is (10) represents the labor supply curve for individuals employed in the nonmandatory overtime sector. Now we do not observe $W_{0}$ for the individual employed in the mandatory overtime sector, rather we observe $W_{1}$, which equals $W_{0}(1+d)$. Hence, (10) can be written

$$
\begin{aligned}
\mathrm{H}_{0} & =\alpha \mathrm{T}+(\alpha-1)\left(M-.5\left(\mathrm{~W}_{1} /(1+\mathrm{d})\right) \overline{\mathrm{H}}\right) /\left(\mathrm{W}_{1} /(1+\mathrm{d})\right)(1.5) & & \text { if } \mathrm{H}_{0}>\overline{\mathrm{H}} \\
& =\alpha \mathrm{T}+(\alpha-1)\left(\mathrm{M}(1+\mathrm{d}) / \mathrm{W}_{1}\right) & & \text { if } \mathrm{H}_{0} \leq \overline{\mathrm{H}}
\end{aligned}
$$

Observe that given $\alpha$, everything on the right-hand side of (11) is known save for $d$. Moreover, for each value of $d$, there will exist a corresponding value of $H_{0}$ and hence of $Y_{0}$ and $L_{0}$. Thus, we can specify the individual's utility from being employed by a firm in which mandatory overtime is not required as a function of the size of the differential

$$
U_{0}(d)=\left(Y_{0}(d)\right)^{\alpha}\left(L_{0}(d)\right)^{1-\alpha}
$$


One can then set (12) equal to (9) and solve for $d^{*}$. The solution will be the fully compensating straight-time wage differential for mandatory overtime; it can be contrasted to the actual differentials that we have estimated.

of course, to proceed along this line first requires an estimate of $\alpha$ and it is natural to obtain such an estimate from the sample of peopie who are employed by firms that do not require mandatory overtime. ${ }^{30}$ That is, for this sample of 943 individuals we estimate a labor supply function of the form (from (10))

$$
\mathrm{H}_{\mathrm{i}}=\alpha \mathrm{T}+(\alpha-1) \mathrm{Q}_{\mathrm{i}}+\varepsilon_{i}
$$

where $Q=(M-.5 W \bar{H}) / 1.5 W$

$$
\begin{aligned}
& \text { if } H>\bar{H} \\
& \text { if } H \leq \bar{H}
\end{aligned}
$$$$
=\mathrm{M} / \mathrm{W}
$$

Estimation of (13) yields an estimate of $\alpha$ of .224, with an estimated standard error of .001. 31

With this estimate in hand, we can compute $U_{1}$, using (9) and the mean values of the variables for individuals employed by firms requiring mandatory overtime. Similarly, we can compute $\mathrm{H}_{0}$ and $\mathrm{U}_{0}$, conditional upon $d$, from (11) and (12). ${ }^{32}$ Finally, equating $U_{0}$ to $U_{1}$ and solving the resulting nonlinear equation for $d$, yields our estimate of the fully compensating straight-time wage differential for mandatory overtime. Our data suggests that this would be approximately 1.1 percent.

This estimate, however, is conditional upon the Cobb-Douglas function being the correct functional form for the utility function. We have used it for illustrative purposes here because it requires us to obtain an estimate of only one parameter $(\alpha)$, and this estimate could be obtained 
directly from estimates of the simple labor supply equation (13). However, because the Cobb-Douglas form is very simple and restrictive, results based on it should be considered only illustrative. While we choose not to proceed any further here because our analyses in the previous section suggested that on average compensating wage differentials for mandatory overtime do not exist, researchers working on similar problems should test the sensitivity of their estimates of the fully compensating differential to alternative assumptions about the functional form of the utility function and/or its parameter values.

\section{Concluding Remarks}

Do employees who are employed by firms in which mandatory assigninent of overtime is required receive compensating straight-time wage differentials? The evidence presented in this paper suggests that on average they do not; this presents some support for the case in favor of legislative prohibition of mandatory overtime. This conclusion should be qualified, however, because in some circumstances, namely for unionized employees and employees with short job tenure with their current employers, compensating wage differentials do exist. Furthermore, the benefits from the legislation must be weighted against the potential costs; these include reduced employer flexibility in scheduling production and consequently increased production costs.

We believe that variants of the methodological framework presented in this paper should prove useful in a number of other contexts for at least two reasons. On the one hand, we have suggested the importance of modeling 
the selection process and controlling for selectivity bias in the estination of compensating wage differentials for undesirable job characteristics. On the other hand, we have developed a framework that permits one to estimate if compensating differentials are in fact fully compensating. The latter is an important step in the analysis which previous investigators, who focused on related topics, often ignored or forgot to undertake. We would be less than honest if we did not acknowledge three major qualifications of the findings we have reported in this paper. First, it is conceivable that the model we used in Section III understates the true magnitudes of the fully compensating wage differential. As noted earlier, it assumes that individuals value only income and leisure time; the disutility from mandatory overtime provisions arises because employees are forced to work more hours than they otherwise would prefer. Suppose, however, that employees also value the way in which overtine hours are distributed across a week and mandatory overtime provisions cause them to lose control over this decision (e.g., "you can't work 1 hour overtime per day like you want but you have to work 5 hours Monday night"). In this case, even if total hours of work were unchanged, employees would still demand a premium for accepting mandatory overtime provisions. The model in Section III does not capture the need for such a premium. Second, software limitations have prevented us from estimating the complete statistical model that is required to control for the joint employee/employer selection problem; the consistency properties of the selectivity adjusted wage equations and the associated wage differentials reported in Tables 1 and 2 are conditional upon the approximation (equation (5)) being a correct one. In addition, our simulations of the fully 
compensating wage differentials assume a very simple, and restrictive functional form for the utility function; future researchers working on similar problems must examine the sensitivity of their results to alternative assumptions about the form of the utility function.

Finally, we should stress that we have focused on the trade-off between wages and mandatory overtime provisions, and ignored all other pecuniary and nonpecuniary job characteristics. Our approach is in the tradition of most of the compensating wage differential literature which focuses on the trade-offs between wages and one nonwage characteristic (e.g., risk of injury or pension coverage) at a time. Implicitly, researchers in this tradition have assumed that the partial correlations between the omitted job characteristics and the included one (holding all other included right-hand side variables constant) are close to zero and thus that the omission causes no omitted variable bias.

It is not obvious that this is always a good assumption to make; a preferred approach would be to analyze the trade-offs between all characteristics simultaneously. However, to appropriately model the more general problem would require selection models for every job attribute and that, coupled with greatly reduced degrees of freedom and possible collinearity problems, may well lead to insignificant results. We suspect that this is why such an assumption is typically made. 
Table 1

Ordinary Least Squares and Selectivity Bias Corrected Least Squares Log Wage Equations and Reduced Form

Probit Model for Mandatory Overtime: 1977

Quality of Employment Survey Data

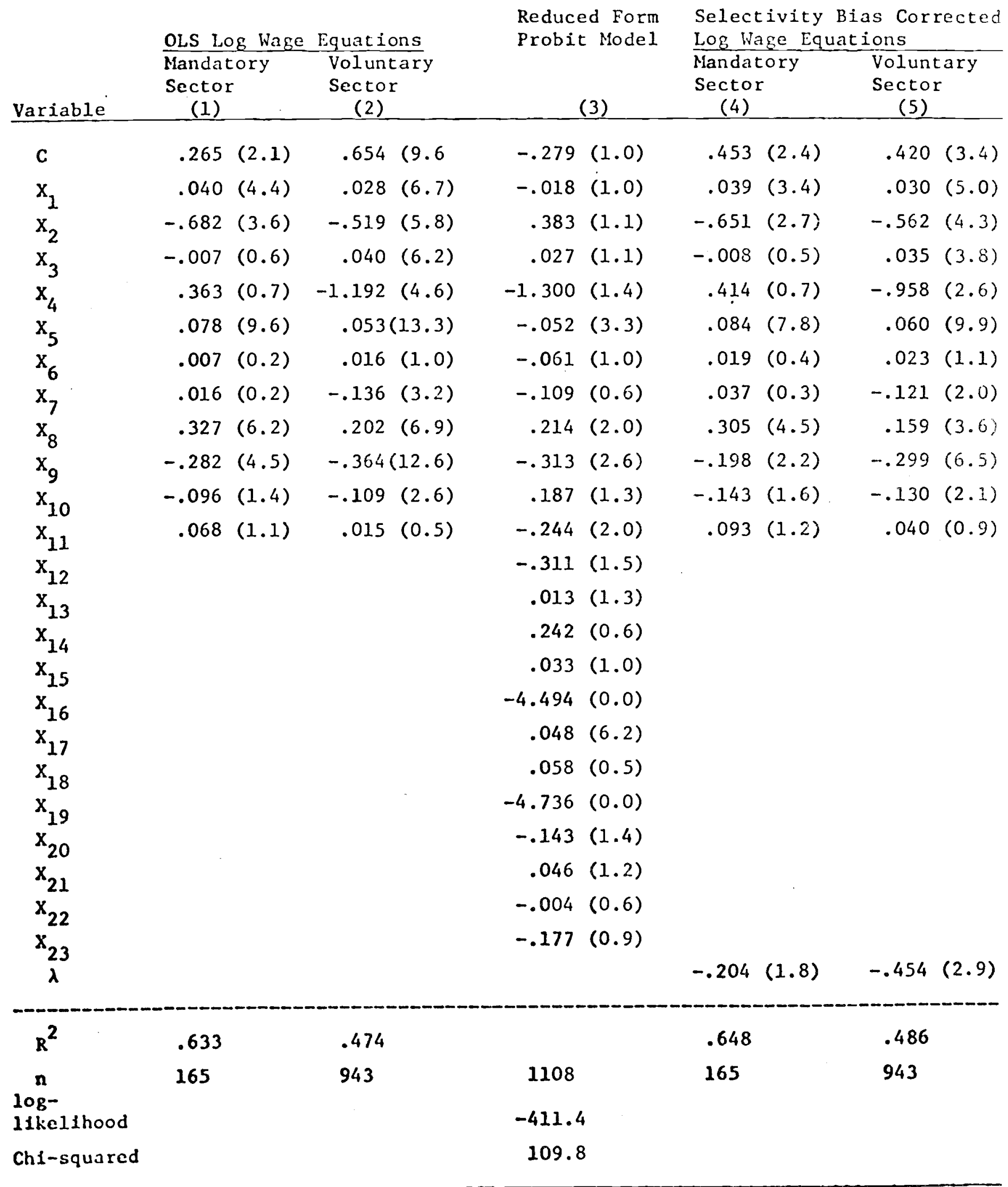


where

C intercept term

$x_{1}$ total years of labor market experience

$x_{2} \quad x_{1}$ squared/1000

$x_{3}$ total years of experience with current employer

$x_{4} \quad x_{3}$ squared $/ 1000$

$\mathrm{X}_{5}$ years of formal school

$\mathrm{x}_{6}$ years of trade school

$x_{7} \quad 1$ =health limits work; $0=$ otherwise

$\mathrm{x}_{8} \quad 1=$ union member or covered by union contract; $0=0$ therwise

$x_{9} \quad l=$ female; $0=$ male

$\mathrm{x}_{10} \quad 1$ =nonwhite; $0=$ white

$\mathrm{x}_{11} \quad \mathrm{l}=$ married, spouse present; $0=0$ otherwise

$\mathrm{x}_{12} \quad 1=\mathrm{employee}$ has a second job; $0=$ otherwise

$x_{13}$ hours of work on second job if reported; $0=0$ thervise

$x_{14} 1$ hours on second job not reported; $0=0$ therwise

$\mathrm{x}_{15}$ size of establishment (number of employees/1000) if reported; 0=otherwise

$\mathrm{x}_{16} \quad \mathrm{l}=\mathrm{size}$ of establishment not reported; $0=0$ therwise

$\mathrm{x}_{17}$ weekly overtime nours

$\mathrm{x}_{18}$ travel time to work if reported; $0=$ otherwise

$x_{19} 1=t r a v e l$ time to work not reported; $0=0$ therwise

$x_{20} \quad 1=$ respondent feels comfort on the job is "okay"; $0=0$ therwise

$\mathrm{x}_{21}$ number of dependents (excluding spouse)

$\mathrm{x}_{22}$ other family members' earnings if reported; 0 =otherhise

$x_{23} 1$ =other family members' eamings not reported; 0 =otherwise

$\lambda$ estimated value of the inverse of the Mills ratio

a The numbers in parentheses are the absolute value of the $t$ ratios for the oLs model, the absolute value of the corrected $t$ ratios for the selectivity bias corrected model, and the absolute value of the asymptotic $t$ ratios for the probit model. 
Table 2

Sumary of Estimated Percentage Straight-Time

Wage Premium Paid to horkers Required to

Work llandatory Overtime: 1977 Quality

of Employment Survey Data ${ }^{a}$

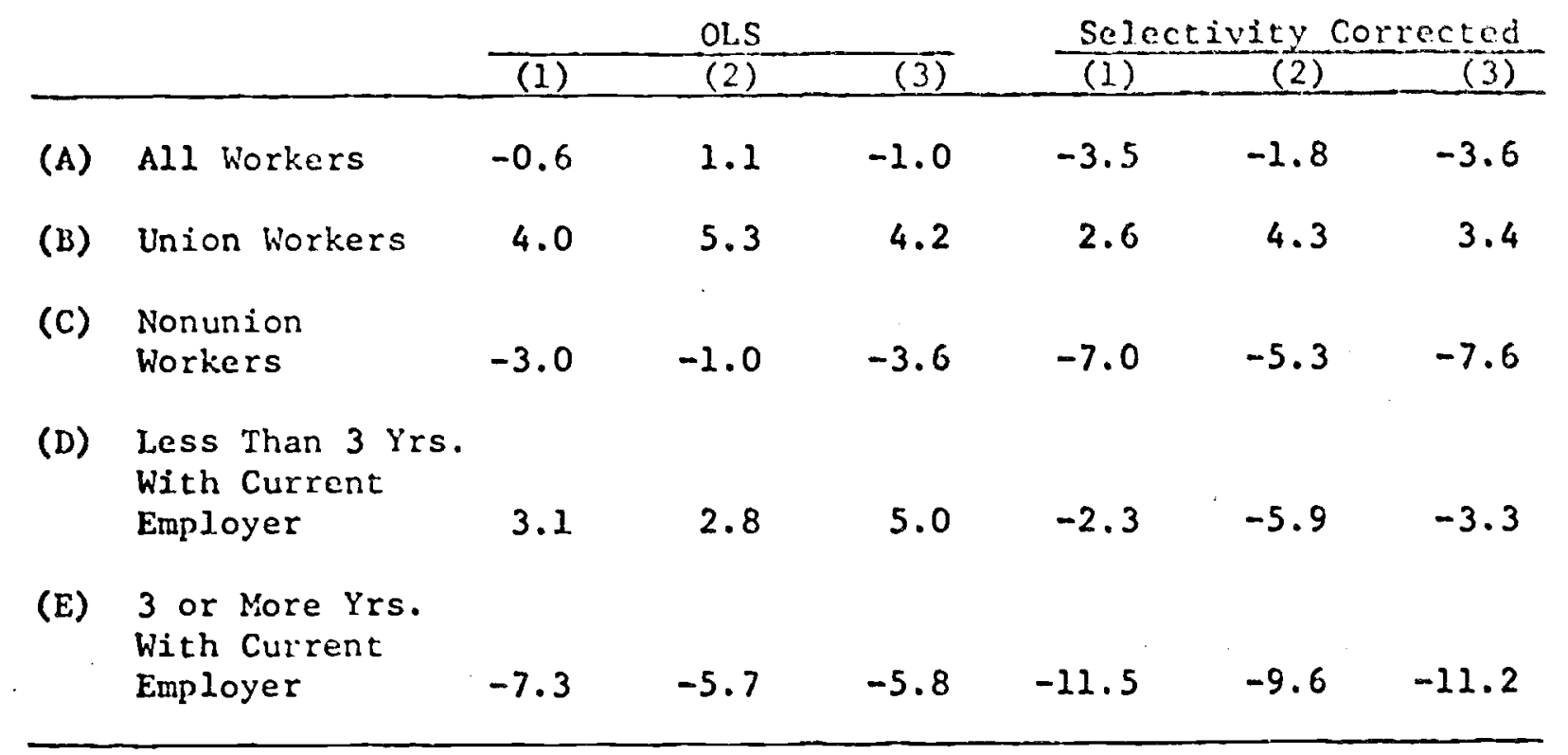

For (A), (B) and (C) separate wage equations were estimated for those people tho worked mandatory overtime and those who did not. The differentials are evaluated in (A) using the nean values of the explanatory variables for all workers, in (3) using the mean values of union workers' characteristics, and in (C) the mean values of nonunion workers' characteristics. For (D) and (E) the two wage equations (mandatory, nonmandatory) are estimated separately for "new" and "experienced" workers and the differentlals computed in an analogous manner. The sample sizes are:

$$
(A, B \text {, and } C) \text { (D) (E) }
$$

mandatory sector

nonmandatory sector
165

943
68

434
97

509

(1) Basic hudan capital model (Including union status).

(2) Basic human capital model plus occupation binary variables.

(3) Basic human capital model plus occupation and Industry blnary vartables. 


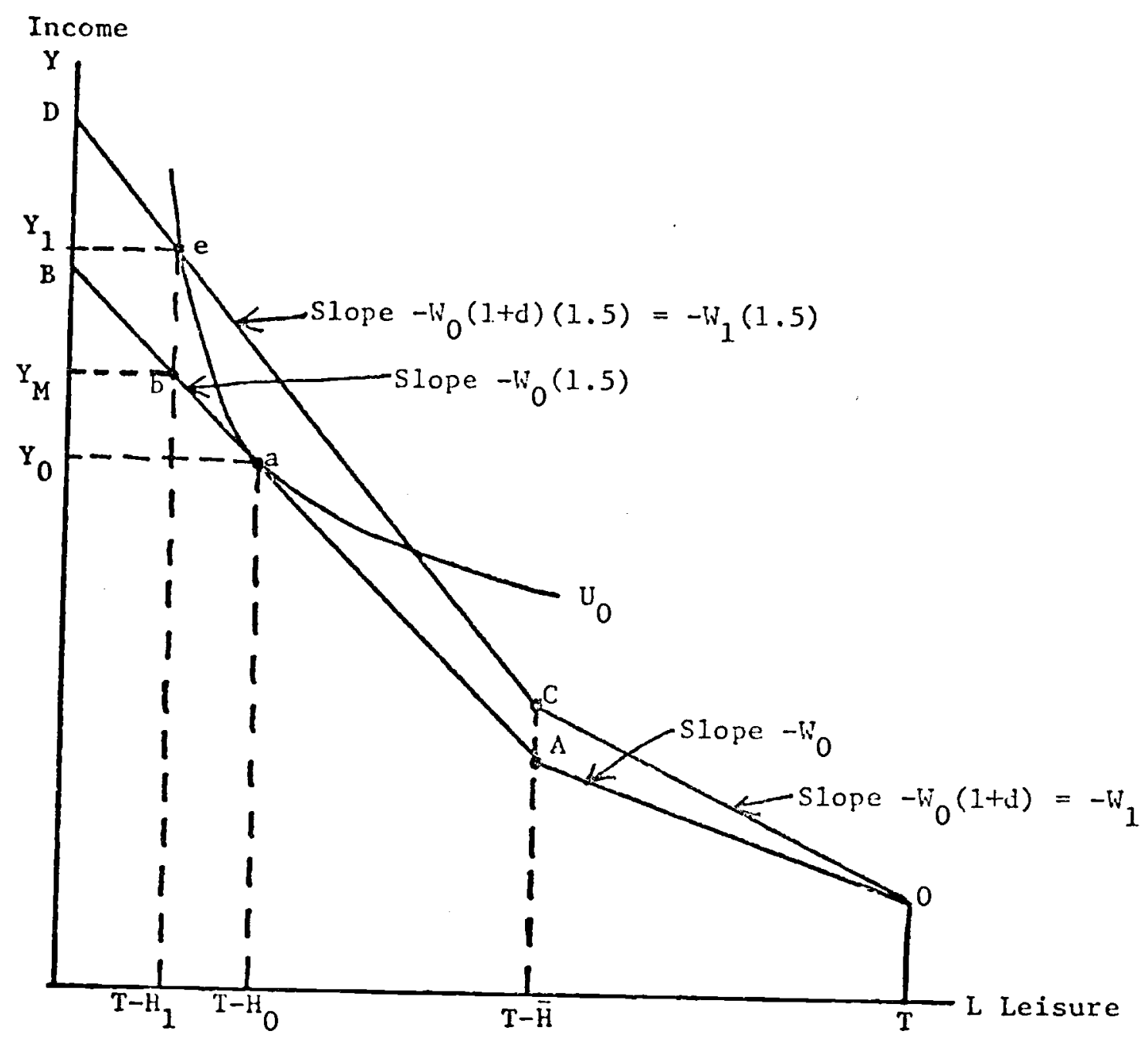

Figure 1

Fully-Compensating Wage Differential for Mandatory Overtime 


\section{$\underline{\text { References }}$}

John Abowd and Orley Ashenfelter. "Unemployment and Compensating Wage Differentials," Princeton University Industrial Relations Section Working Paper No. 120, March 1979.

Gary Becker. Human Capital. Columbia University Press, New York, NY. 1964. Charles Brown and James Medoff. "Trade Unions in the Production Process," Journal of Political Economy. June 1978.

Kim Clark. "The Impact of Unionization on Productivity: A Case Study," Industrial and Labor Relations Review. July 1980.

Alan Deardorff and Frank Stafford. "Compensation of Cooperating Factors," Econometrica. July 1976.

Greg Duncan. "Earnings Functions and Nonpecuniary Benefits," Journal of Human Resources. Fall 1976.

Greg Duncan and Frank Stafford. "Do Union Members Receive Compensating Wage Differentials?," American Economic Review. June 1980.

Ronald Ehrenberg. "Retirement System Characteristics and Compensating Wage Differentials in the Public Sector," Industrial and Labor Relations Review. July 1980 .

Ronald Ehrenberg and Paul Schumann. "The Overtime Pay Provisions of the Fair Labor Standards Act." In Simon Rottenberg, ed., The Economics of Legal Minimum Wages (American Enterprise Institute, Washington, D.C., 1981). Ronald Ehrenberg and Paul Schumann. Longer Hours or More Jobs (New York State School of Industrial and Labor Relations Publications Division, Ithaca, NY, 1982). 
Richard Freeman and James Medoff. "The Two Faces of Unionism," Public Interest, Fall 1979.

James Hecknan. "Sample Selection Bias as a Specification Error," Econometrica. January 1979.

- "Sample Selection Bias as a Specification Error: With An Application to the Estimation of Labor Supply Functions," in James P. Smith, ed., Female Labor Supply: Theory and Estimation. Princeton University Press, Princeton, NJ. 1980.

Lung-Fei Lee. "Unionism and Wage Rates: A Simultaneous Equations Model With Qualitative and Limited Dependent Variables," International

Economic Review. June 1978.

James Medoff. "Layoffs and Alternatives Under Trade Unions in U.S. Manufacturing," American Economic Review. June 1979.

National Board for Prices and Income. Hours of Work, Overtime, and Siniftiork.

Report No. 61. London, England. 1970.

Dale Poirer. "Partial Observability in Bivariate Probit Models," Journal of Econometrics. February 1980.

Robert Quinn and Graham Staines. The 1977 Quality of Employment Survey: Descriptive Statistics. Ann Arbor, Michigan. 1979.

Robert S. Smith. The Occupational Safety and Health Act: Its Goals and Achievements. American Enterprise Institute, Washington, D.C. 1976. - "Compensating Wage Differentials and Public Policy: A Review," Industrial and Labor Relations Review. April 1979. 
Richard Thaler and Sherwin Rosen. "The Value of Saving a Life: Fvidence From the Labor Market," in Nester Terleckyj, ed., Household Production and Consumption. National Bureau of Economic Research, New York. 1975. U.S. Bureau of Labor Statistics. Characteristics of Major Collective Bargaining Agreements, July 1, 1976. Bulletin 201. Washington, D.C. February 1979. 


\section{Footnotes}

1. See National Board for Prices and Income (1970).

2. HR 1784 introduced into Congress on February 1, 1979.

3. A more extensive discussion of this conceptual framework, and of how the history of hours of work legislation in the United States relates to it, is presented in Ronald G. Ehrenberg and Paul L. Schumann (1981).

4. Robert Quinn and Graham Staines (1979), pp. 90-91.

5. U.S. Bureau of Labor Statistics (1979).

6. Such compensating differentials can also be viewed as an insurance payment made by employers, who are faced with the need for regularly scheduled overtime or with random fluctuations in their demands for overtine, to guarantee them the availability of the appropriate number and skill. mix of employees to work overtime. Viewed in this way, prohibitions against mandatory overtine would limit the freedom of the parties to agree to the issuance of such "insurance policies".

7. A separate policy issue is whether the overtime pay premium required under the FLSA should be raised from time-and-a-half to double-tiine in the hopes that this would reduce employers' usage of overtime hours and stimulate employment growth. We discuss this issue in detail in Ehrenberg and Schumann, (1982).

8. If one had longitudinal data one could estimate the extent to which changes in overtime hours provisions were correlated with changes in straighttime wages over time, other things equal. An example of the use of longitudinal data in a similar context is Greg Duncan and Frank Stafford (1980) who use the Michigan Incone Dynamics Panel data to analyze the interrelationship between changes in unionization, wages, and two other working conditions. 
9. See James Heckman (1979) and Lung-fe.i Lee (1978).

10. See Alan Deardorff and Frank Stafford (1976) who point out that in situations in which such complementarities exist, that straight-time wage differentials might arise to compensate workers for workday lengths that depart from those that they would freely choose, given their alternative wage rates.

11. See Ehrenberg and Schumann (1982) for a more complete description of the model.

12. Dale Poirer (1980).

13. One must caution, however, that because we have only approximated the true sample selection rule with a univariate probit model, the statistical properties of our estimates of (2) and (3) when we control for selectivity bias are not obvious. That is, their consistency is conditional upon (5) being the correct underlying selection rule (see Poirer (1980)).

14. The conventionally reported OLS standard errors are inappropriate, however, since the estimated values of the inverse of the Mills ratio (the $\lambda$ in Table 1) are estimated from data in a previous stage. Heckman (1979) derives a method to consistently estimate the correct standard errors, and the results reported in Table 1 in tine next section present these estimates. Unfortunately, as Heckman (1980) notes, this procedure may lead to negative estimated standard errors in finite samples and whenever this occurred the conventional OLS estimates were reported in the table instead.

15. For a complete description of these data, see Quinn and Staines (1979).

16. The complete results, both here and below, are reported in Ehrenberg and Schumann (1982). 
17. We must caution that sone of these variables (e.g., overtime hours, hours on second job or extent of unionization (see Duncan and Stafford (1980)) are undoubtedly simultaneously determined with the presence of mandatory overtime provisions. To keep our problem manageable, we treat all of the variables in column 3 of Table 1 as being predetermined. We did experiment with omitting overtime hours from the reduced form probit equation; such an omission actually increased the magnitude of the compensating wage differential for mandatory overtime above the level that we report below.

18. See Ehrenberg and Schumann (1982) for a discussion of why each of the explanatory variables enters the probit equation and its expected sign.

19. Our estimation of the "selectivity corrected" wage equations were facilitated by our colleague William Greene, who provided us with a computer program he has written to estimate such models.

20. For an excellent expository survey of this literature, see Richard Freeman and James Medoff (1979).

21. See, for example, Charles Brown and James Medoff (1978), Kin Clark (1980), and James Medoff (1979).

22. Duncan and Stafford (1980).

23. The sample sizes available were unfortunately too small to permit us to reestimate the model separately for union and nonunion employees and then to base estimated differentials on such equations.

24. See Gary Becker (1964).

25. This statement should be qualified by noting that if, ex ante, Job applicants expect to have long tenures with a firm and they are aware that an unfavorable working condition exists or may be instituted at the firm in the future, then they would accept employment only if they expected to receive compensating differentials throughout their tenure with the firm. 
Footnote 25 continued:

Our argument in the text essentially assumes that the unfavorable working condition was imposed unexpectedly (to them) sometime after the initial hire date.

26. For risk of injury, see Robert S. Smith (1976) and Richard Thaler and Sherwin Rosen (1975). For nonwage forms of compensation, see Ronald Ehrenberg (1980). For working conditions, see Greg Duncan (1976) and Duncan and Stafford (1980). Finally, for risk of unemployment, see John Abowd and Orley Ashenfelter (1979).

27. Robert Smith (1979).

28. The assumption that the individual would voluntarily choose to work overtime is not essential to what follows.

29. Our analysis assumes that the individual is concerned about total hours of leisure in a week not how it is allocated across days. If he was concerned about the latter, he might require a premiun to be employed by a firm requiring mandatory overtime even if $\mathrm{H}_{0}$ was equal to $\mathrm{H}_{1}$. This is a complication which we do not deal with here. We should also emphasize that the fully-compensating premium is a function of the gap between $\mathrm{H}_{1}$ and $\mathrm{H}_{0}$, not of the level of overtime that the individual actually works.

30. This procedure assumes that $\alpha$ is the same for individuals in both sectors -- an assumption that is somewhat inconsistent with the model discussed previously in which individuals are "sorted" into the mandatory sector at least partially on the basis of their willingness to work overtime. other things equal, we should expect to observe individuals with lower marginal utilities of leisure (higher $\alpha^{\prime} s$ ) to be in the mandatory sector. As a result, the estimates of $\alpha$ which we obtain below from data on 
Footnotes 30 continued:

Individuals in the voluntary overtime sector will. likely understate the true values of a for individuals in the mandatory sector. Since one can show that an increase in $\alpha$ will lead to a decrease in the magnitude of the fully-compensating wage differential, the value of $d^{*}$ which we report below may well overstate the true fully-compensating differential.

31. Variants of (13) were also estimated in which $\alpha$ was specified to be a function of an individual's sex, race, marital status, health status, and number of dependents. When evaluated at the mean values of these variables for individuals employed by firms that required mandatory overtime, the resulting estimate of $\alpha$ was almost identical (.223) to the value reported in the text.

This estimate and the one in the text imply that the marginal propensity to consume out of unearned income is less than one-quarter, a result that is much smaller than other investigators have found. As noted in footnote 30 , however, larger values of a would lead to even smaller values of the fullycompensating differential.

32. The parameters used in this simulation are $T=168, \mathrm{~W}_{1}=\$ 6.026$, $\mathrm{H}_{1}=45.139, \overrightarrow{\mathrm{H}}=40$, and $\mathrm{M}=\$ 80.615$; the latter represents all family income except for the respondent's labor earnings including the labor earnings of other family members. The QES data unfortunately did not permit us to compute family nonlabor income which theoretically is the more appropriate variable to use, unless the respondent's labor supply is conditional on other family members' labor supply decisions. 